\title{
Immunolocalization of CD18-positive cells in the bovine ovary
}

\author{
K. Spanel-Borowski, P. Rahner and A. M. Ricken \\ Department of Anatomy, University of Basle, Pestalozzistr. 20, CH-4056 Basle, Switzerland
}

\begin{abstract}
The life cycle of follicles and of corpora lutea may be finely tuned by resident leucocytes in control of the angiogenesis, dilatation and permeability of microvessels, remodelling of the extracellular matrix, and phagocytosis of degenerated cells. Since the overall leucocyte distribution has not been studied in the bovine ovary, we located the CD18 molecule in this organ using indirect immunohistochemistry. This molecule represents a subtype of $\beta_{2}$ integrin and is expressed by all subsets of leucocytes. The microvessels were also identified with an antibody against factor VIII antigen. The outer layer of the interstitial cortex, where the primordial follicles were located, contained a few CDI8-positive cells and a few microvessels. Intact follicles displayed the CD18-positive cells in the theca. They were aligned in the zone of the basal membrane of preovulatory follicles. This was associated with a dilated inner microvessel layer. CD18-positive cells and probably capillary sprouts were seen in the granulosa layer of freshly ovulated follicles. Regressing follicles exhibited CD18-positive cells in the hypertrophied theca and in the degenerating granulosa layer, together with the pattern of capillary sprouts. At the developmental stage, corpora lutea exhibited many CD18-positive cells in the septa. The microvascular bed was expanding. At the secretory stage, a regular and moderate appearance of CD18-positive cells corresponded to a well-developed microvascular bed. Abundant positive cells were seen at the regressive stage, together with the development of shunt-like arterioles. The semiquantitative evaluation of leucocyte subsets in corpora lutea revealed an increase in the CD18-positive cells between stages of development and regression, which was not observed in the corresponding interstitial cortex. Lymphocytes with the expression of CD2, CD3 or both molecules displayed a similar behaviour. In conclusion, the CD18-positive leucocytes represent a heterologous pool with a distribution that varies in accordance with morphological changes in the follicles and corpora lutea.
\end{abstract}

\section{Introduction}

Growth, regression and remodelling of the microvascular bed determine the life cycle of follicles and corpora lutea (Findlay, 1986; Koos, 1989; Reynolds et al., 1992). Apoptotic cell death of granulosa cells and of luteal cells contributes to the gradual disappearance of these cell types (Hughes and Gorospe, 1991; Juengel $e t$ al., 1993). Resident macrophages remove the apoptotic cells by phagocytosis. This is considered to be the classical macrophage function during luteolysis (Paavola, 1979; Hehnke et al., 1994). Fibrosis with hyalinization finally replaces regressed follicles and corpora lutea. It is evident that, in the ovary, important processes develop under physiological conditions which, under pathological conditions, are associated with inflammation and neoplasia.

Resident leucocytes of different subsets play a powerful role in the cyclically changing ovarian structures (Adashi, 1990, 1991). In the wall of preovulatory rat follicles compared with antral follicles, the increased presence of both neutrophils and macrophages has recently been reported by Brännström et al.

Present address: K. Spanel-Borowski, Institute of Anatomy, University of Leipzig, Liebigstrasse 13, D-04103 Leipzig, Germany.

Received 7 March 1997.
(1993). These leucocytes may secrete factors that play a key part in the ovulatory events such as dilatation, permeability and sprouting of microvessels, as well as in the degradation of the basal membrane. Macrophages are involved in vessel sprouting and in degradation of the extracellular matrix by means of their secretion of angiogenic and proteolytic factors (Sunderkötter et al., 1994). In addition, eosinophils and mast cells are present in preovulatory follicles. These leucocytes probably induce local vasodilatation and vascular permeability, because eosinophilic or mast cell granules release histamine and prostaglandin $\mathrm{F}_{2 u}$ after the LH surge (Nakamura et al, 1987; Murdoch and McCormick, 1989). After follicle rupture, eosinophils and macrophages are seen to invade the luteinizing granulosa layer (Cavender and Murdoch, 1988; Simón et al., 1994). The presence of macrophages may be required for luteinization, because human and mouse granulosa cells increase progesterone production in coculture with peritoneal and luteal macrophages (Kirsch et al., 1981; Halme et al., 1985). At the time of luteolysis, eosinophils and macrophages, which further increase in number, seem to be involved in the degradation and removal of the luteal tissue (Murdoch, 1987; Hehnke et al., 1994). In preovulatory follicles and in corpora lutea, a few $\mathrm{T}$ lymphocytes have always been observed 
Table 1. Monoclonal mouse antibodies against bovine leucocyte molecules obtained from two companies

\begin{tabular}{lccc}
\hline $\begin{array}{l}\text { Surface } \\
\text { antigen }\end{array}$ & $\begin{array}{c}\text { Cell } \\
\text { specificity }\end{array}$ & $\begin{array}{c}\text { Antibody clone of } \\
\text { the IgG1 subtype }\end{array}$ & Immunoresponse \\
\hline $\begin{array}{l}\text { Antibodies supplied by VMRD, Pullman, WA } \\
\text { CD18 }\end{array}$ & Pan-leucocytes & & \\
CD45 & Pan-leucocytes & BAQ 30 A & Positive \\
Unknown & Monocytes, lymphocytes, granulocytes & CACT B 31 A & Positive \\
CD2 & Pan-lymphocytes (sheep red blood cell acceptor) & DH 59 B & Positive \\
CD3 & T lymphocytes 9 A & Positive \\
CD4 & T helper cells & MM 1 A & Positive \\
CD8 & Cytotoxic T cells & CACT 138 A & Negative \\
Antibodies supplied by Serotec, Oxford, UK & CACT 80 A & Negative \\
CD2 & Pan-lymphocytes & & Positive \\
CD4 & T helper cells & CC 42 & Negative \\
CD8 & Cytotoxic T cells & CC 30 & Negative \\
CD14 & Monocytes & CC 63 & Positive \\
CD26 & Activated T cells & VPM 65 & Negative \\
\hline
\end{tabular}

without any marked change in the number during the stages of the oestrous cycle (Bagavandoss et al., 1990; Brännström et al., $1994 a, b)$.

Since the total pool of leucocytes has not been indisputably located in any mammalian ovary, the aim of the present study was to give a thorough morphological review of the distribution of all leucocytes in the follicular, the luteal and the interstitial cortical compartment of the bovine ovary. Because ovarian leucocytes are suspected to influence microvessels, these are also indicated. The technique used was indirect immunohistochemistry combined with the application of a common leucocyte antibody able to recognize bovine $\beta_{2}$ integrin of the CD18 subtype, which is found on all subsets of leucocytes. For the semiquantitative approach, specific bovine antibodies against surface molecules were available for differentiating between cells of the monocyte-macrophage lineage or lymphocytes, although antibodies against granulocyte surface molecules were not used.

\section{Materials and Methods}

Ovaries for the study of follicles were obtained from cows immediately after death at the local abattoir. The selected animals showed corpora lutea in one ovary, thus indicating the maintenance of the reproductive cycle. The other ovary contained antral follicles of $1-2.5 \mathrm{~cm}$ diameter $(n=28)$. In addition, four freshly ovulated follicles were diagnosed by a tiny lesion of the surface epithelium showing beneath a gyrated dark red structure approximately $5 \mathrm{~mm}$ in depth. Pieces of the follicle wall together with the adjacent interstitial cortex were carefully dissected, immediately shock frozen in propane and stored at $-20^{\circ} \mathrm{C}$ until required.

Ovaries for the study of corpora lutea were obtained from nonpregnant cows. Pregnancy was excluded by incision of the uterine horns for the presence of a fetus. The ovaries were removed together with the mesovarian tissue. After the coiled ovarian artery had been prepared, a cannula was inserted into the vessel lumen, and $10 \mathrm{ml}$ PBS containing 100 i.u. heparin $\mathrm{ml}^{-1}$ applied with a syringe under manual pressure. The successful vessel rinse was indicated when a corpus luteum became pale. Luteal tissue pieces, together with the adherent cortical tissue, were removed, shock frozen, and stored as described. The corpora lutea were classified according to the stage of development between days 1 and 4 of the oestrous cycle $(n=7)$, of early secretion between days 5 and $10(n=7)$, of advanced secretion between days 11 and $17(n=7)$, or of regression between days 18 and $21(n=3)$. The different oestrous cycle stages were determined according to the size, consistency, and colour of the corpora lutea, and to the histological criteria described by Ricken et al. (1995).

Indirect immunohistochemistry was carried out using the method described by Ricken et al. (1995) to locate resident leucocytes and to show microvessels. In brief, $10 \mu \mathrm{m}$ cryostat sections were mounted on object slides coated with Cementit $R$ (Merz and Benteli AG, Niederwangen). The sections were immediately fixed with ice cold absolute acetone for $5 \mathrm{~min}$, and then treated with $0.3 \% \mathrm{H}_{2} \mathrm{O}_{2}$ in absolute methanol to inactivate endogenous peroxidase activity. They were rehydrated with $0.05 \mathrm{~mol}$ Tris-buffered saline $1^{-1}, \mathrm{pH} 7.6$. This was the wash buffer used throughout the procedure to reduce backgound staining. The sections were treated with 1.5\% normal rabbit or goat serum depending on the species of the second antibody.

Leucocytes were detected with the mouse monoclonal antibody $\mathrm{BAQ} 30 \mathrm{~A}$ (VMRD, Inc. Pullman, WA) recognizing bovine $\beta_{2}$ integrin of the CD18 subtype. This integrin is known to be expressed by all leucocytes (Bosman, 1993). Comparable monoclonal antibodies from VMRD and from Serotec (Oxford) were investigated to confirm the results for the CD2, CD4 and CD8 molecules. In addition, to detect CD14 or CD26 molecules on monocytes or activated T lymphocytes, specific monoclonal antibodies were purchased from Serotec (Table 1). Endothelial cells of microvessels were located with a polyclonal rabbit antibody against human factor VIIIr antigen (DAKO, Zürich). The primary leucocyte antibodies were diluted $1: 100$ in PBS with $0.25 \%$ bovine serum albumin, with exceptions of the following antibodies: the BAQ $31 \mathrm{~A}$ 
(anti-CD18), the BAQ 95A (anti-CD2) with a 1:500 dilution and the VPM65 (anti-CD14) with a 1:5 dilution. The anti-factor VIIIr antibody was diluted 1:1000. Incubation was carried out in a humid chamber at $4^{\circ} \mathrm{C}$ overnight.

The subsequent immunolabelling was carried out with the Vectostain Elite ABC kit (Vector, Geneva). This consisted of biotinylated second antibodies from either rabbit or goat, and the avidin-horseradish peroxidase complex for detection of the bound immunoglobulins. Peroxidase was developed with 3-amino-9-ethylcarbazole (Sigma). Nuclei were counterstained with haematoxylin. Sections were mounted in Crystal Mount (Stehelin and Co., Basle), a water soluble embedding medium. Micrographs were taken with a Polyvar light microscope from Reichert-Jung.

Semiquantitative evaluation was carried out as far as possible to subtype the CD18-positive cells with other leucocyte antibodies and to quantify the leucocyte subsets in sections of the luteal tissue and of the interstitial cortex. An ocular grid of $0.05 \mathrm{~mm}^{2}$ at a $\times 40$ objective magnification was used to determine the number of positively stained cells. The evaluation was started somewhere at the periphery of a corpus luteum and, at regular intervals, continued to count ten areas whether they happened to be luteal tissue or luteal septa. The interstitial cortex adjacent to the corresponding corpus luteum was examined in a similar way. Distinct microvessels, follicles and the outer layer of the interstitial cortex were excluded from the evaluation. After the number of the positively stained cells had been obtained for each luteal or cortical sample, the mean number $\pm S D$ in an area of $0.5 \mathrm{~mm}^{2}$ was calculated for the development, advanced secretion or regression groups. Student's $t$ test was applied to verify statistically significant differences between the groups.

\section{Results}

\section{Immunohistochemistry of CD18-positive cells}

A moderate number of CD18-positive cells was detected in the interstitial cortex, apart from in its outer layer (Fig. 1a) The outer layer, $350-450 \mu \mathrm{m}$ in width, consisted of spino-cellular connective tissue and lay adjacent to the tunica albuginea, which was $130-160 \mu \mathrm{m}$ thick. Only the outer layer contained some primordial and primary follicles. The CD18-positive cells were more or less absent from the outer layer. The number of microvessels sharply declined until they were undetectable in the outer layer in comparison with the inner layer (Fig. 1b)

Healthy antral follicles revealed a particular distribution of CD18-positive cells depending upon the follicle type. Antral follicles appeared to host more positive cells in the outer layer of the theca than in the inner layer (Fig. 1c), although the microvessels seemed regularly distributed within both layers (Fig. Id). Five of the 28 antral follicles were preovulatory follicles as deduced from the gyrated granulosa layer. The CD18-positive cells were aligned in the area of the basal membrane together with a conspicuous layer of microvessels (Fig. Ie, f). The granulosa layer of the four freshly ovulated follicles contained the positive cells (Fig. 1g). A factor VIIIr-positive response in the granulosa layer was reminiscent of the delicate arborization that may be expressed by sprouting capillaries without a vessel lumen (Fig. 1h). Dilated microvessels were apparent in the oedematous theca.

The corpora lutea underwent the changes characteristic of each stage of the oestrous cycle. At the developmental stage, the thecal infoldings were densely populated by CD18-positive cells, while the infolded granulosa lutein tissue displayed a sparse population of these cells (Fig. 2a). The infoldings of the thecal layer contained small endocrine-like cells and dilated microvessels. The small microvessels of the granulosa lutein tissue stained weakly and irregularly for the factor VIIIr antigen (Fig. 2b). In the secretory stage, a small to moderate number of CD18-positive cells was distributed uniformly in the luteal tissue and in the thin connective tissue septa (Fig. 2c). A dense capillary-like meshwork was now apparent (Fig. 2d). At the advanced secretory stage, the number of positive cells seemed to have increased in comparison with the early secretory stage (Fig. 2e). The increase in the CD18-positive cells during the advanced secretory stage was accompanied by a decrease in the microvessel density (Fig. 2e). The capillary-like structures disappeared and, in places, arterioles developed (Fig. 2f). In the regression stage, luteal cells were replaced by the CD18positive cells. When the positive cells had assembled in a patchy pattern, luteal cells were still seen. When the CD18positive cells were consistently crowded, luteal cells could not be detected. Arterioles with walls of various thicknesses became apparent (Fig. 2g, h).

Follicles were studied in different stages of atresia. At the early stage with the antrum still present, the granulosa layer was uneven in thickness. The granulosa cell nuclei were irregular in size, condensed and fragmented, and resembled apoptotic bodies. A considerable number of CD18-positive cells was detected in the inner and the outer thecal layer (Fig. 3a). The positive cells had invaded the granulosa layer and were found in the antrum. Microvessels were well developed as long as the thecal layer showed hypertrophy (Fig. 3b). In the advanced stage, follicles were obliterated by fibrotic organization. This situation could correspond to a moderate or a large number of CD18-positive cells (Fig. 3c, e). Microvessels appeared to be maintained in the regressing theca, and ingrowth of sprouting capillaries could be deduced from the delicate factor VIIIr-positive arborization pattern (Fig. 3d, f). The very late stage consisted of complete fibrosis accompanied by the sparse population of CD18-positive cells and by poor microvascularization (Fig. 3g, h).

\section{Semiquantitative evaluation of leucocyte subsets}

Corpus luteum. The number of leucocytes increased significantly from the development to the regression stage (Table 2). By using three different antibodies, capable of recognizing the CD18 or the CD45 molecules as well as the DH 59B antibody with detection of granulocytes, monocytes and macrophages, similar results were found at the development stage. The number of positively reacting cells detected with the three different antibodies seemed comparable to those found at the advanced secretory stage, taking into account the high range values. At the regressive stage, cells were densely crowded and it was impossible to determine individually positively stained cells. Monocytes, identified by the occurrence of 
(a)

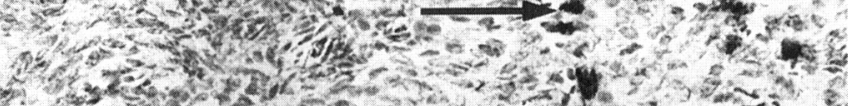

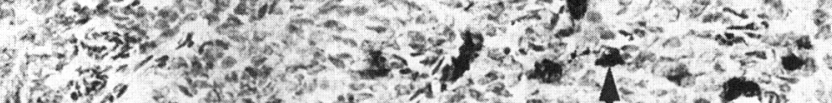

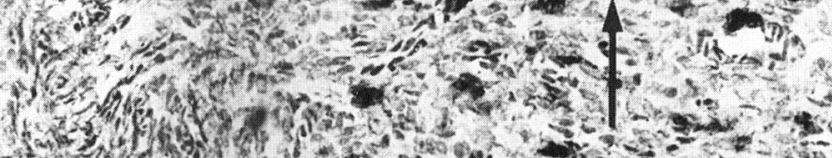

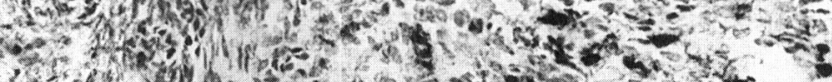

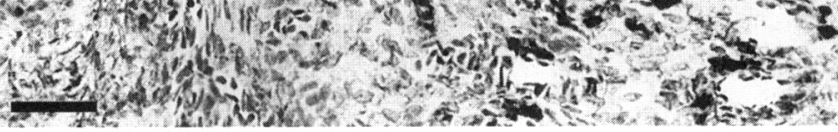

6.(C)

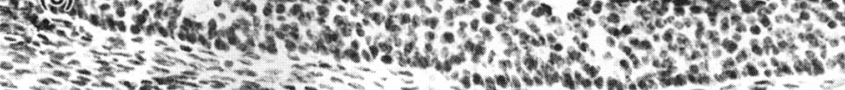
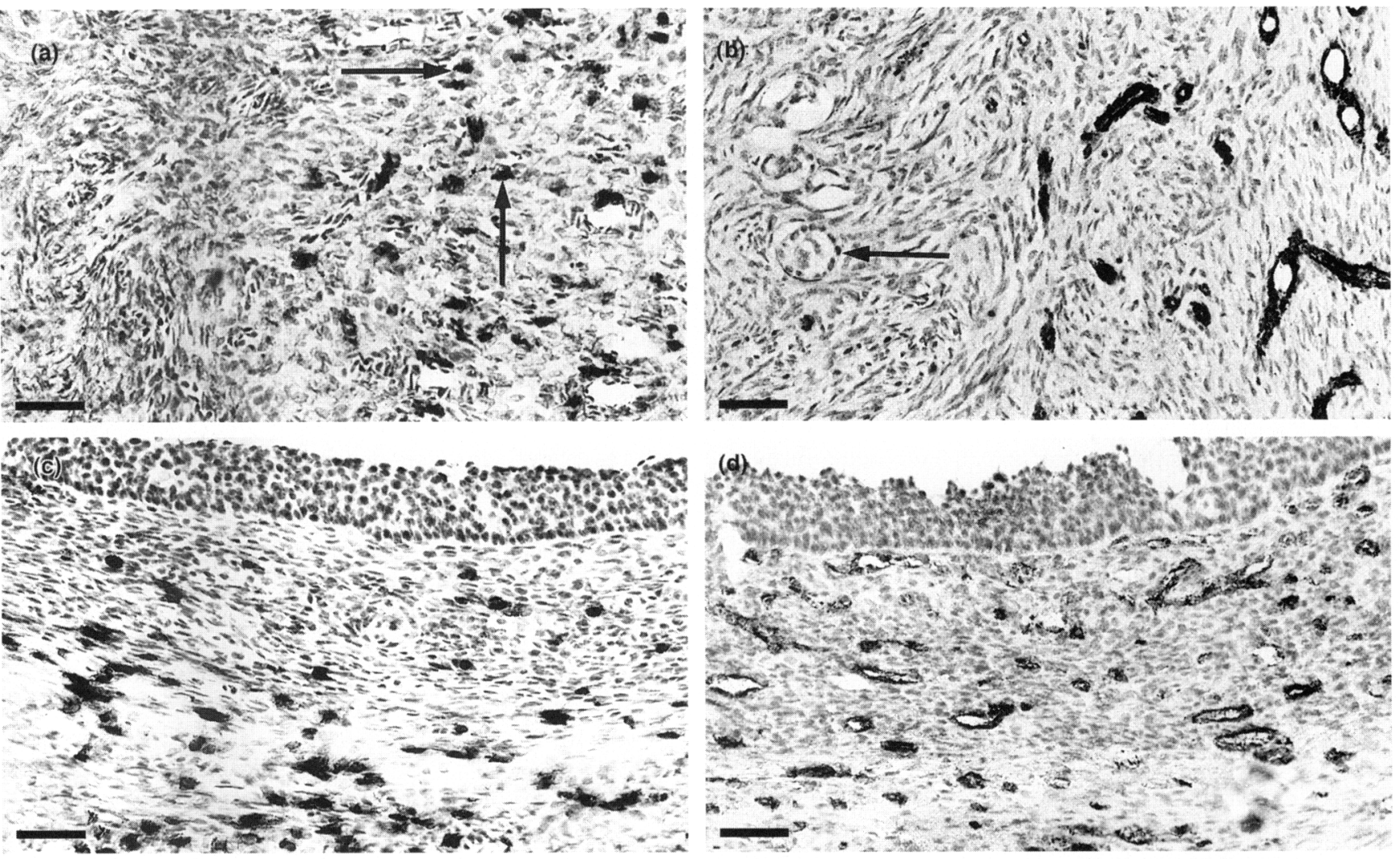

(e)

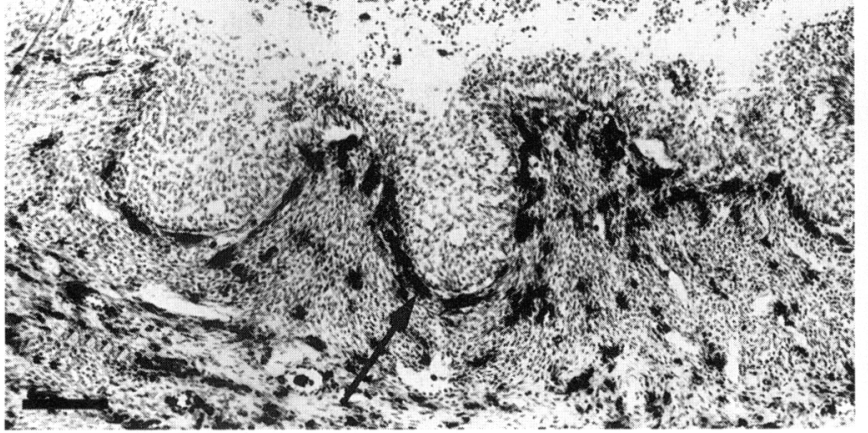

(g) Pot o

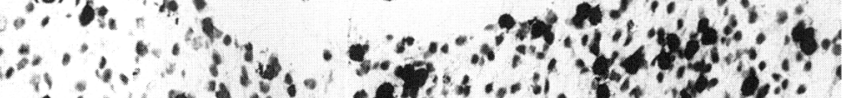
- 5.

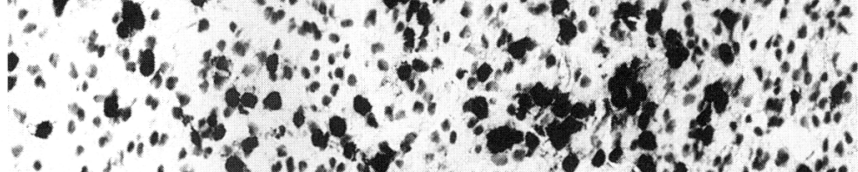
:

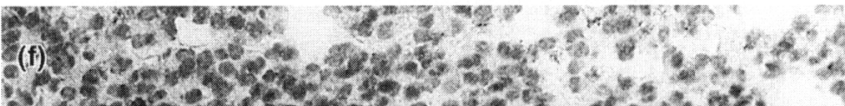

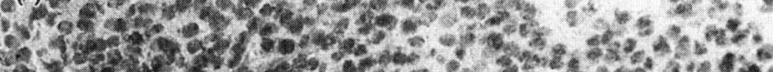
W S-2. 2 a

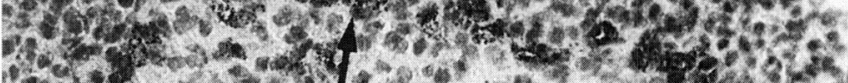

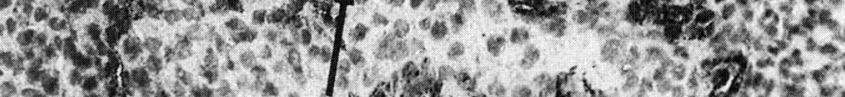

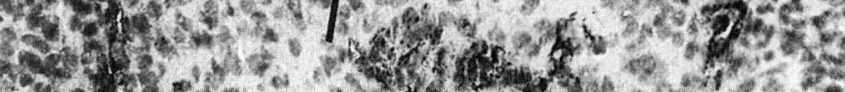

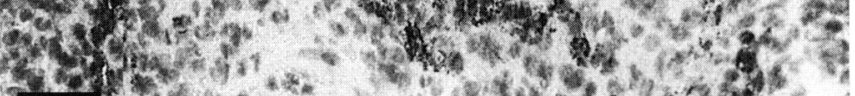

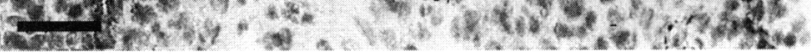

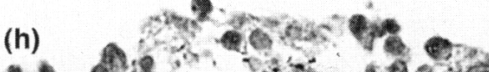

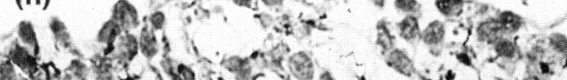

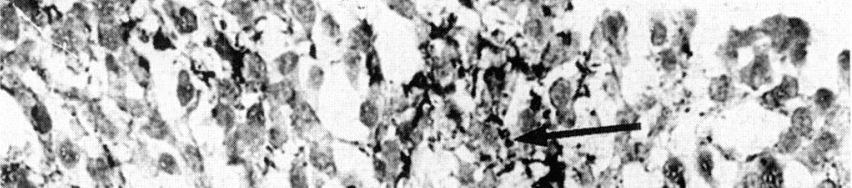

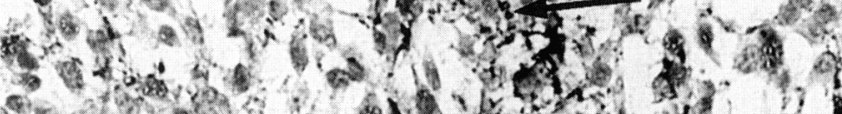

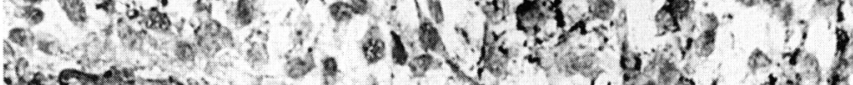

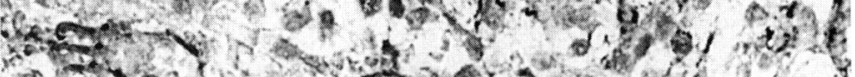

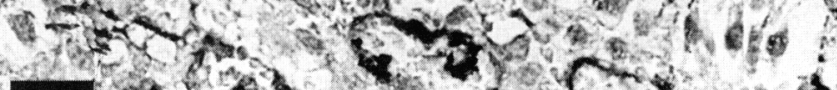

Fig. 1. Cryostat sections of the bovine ovary stained with indirect immunohistochemistry. The sections on the left (a, $c, e, g$ ) show the CD18-positive cells. The sections on the right $(\mathrm{b}, \mathrm{d}, \mathrm{f}, \mathrm{h})$ demonstrate the microvessels in a corresponding area using a polyclonal antibody against factor VIIIr antigen. (a) CD18-positive cells (arrows) are widely absent in the outer layer of the interstitial cortex. (b) The outer layer represents a sparsely vascularized zone. It consists of spino-cellular connective tissue and shows a primordial follicle (arrow). (c) The outer thecal layer of an antral follicle appears to contain more CD18-positive cells than the inner layer. (d) Microvessels seem to be regularly distributed in the theca. (e) The preovulatory follicle is diagnosed by the infolded granulosa layer. The CD18-positive cells are aligned in the zone of the basal membrane (arrow). (f) An inner microvessel layer is conspicuous in the zone of the basal membrane (arrow). (g) A freshly ovulated follicle has been invaded by the CD18-positive cells. (h) The theca shows dilated microvessels and a loose texture due to oedema. The delicate arborization pattern with a factor VIIIr immunoresponse probably indicates vessel sprouts in the granulosa layer (arrow). Scale bars represent $50 \mu \mathrm{m}(\mathrm{a}, \mathrm{b}, \mathrm{c}, \mathrm{d}, \mathrm{f}, \mathrm{g}), 100 \mu \mathrm{m}$ (e) and $20 \mu \mathrm{m}(\mathrm{h})$. 


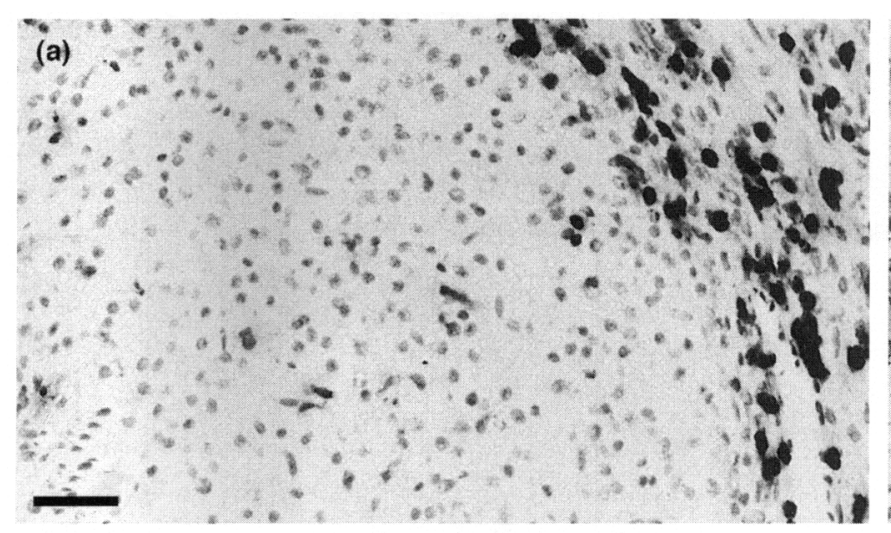

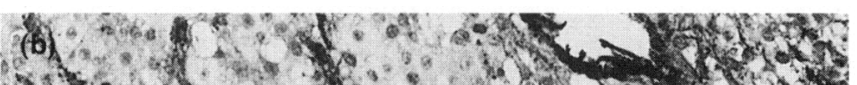

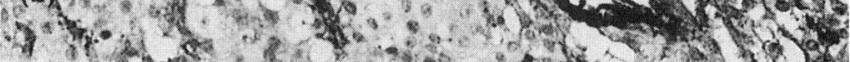

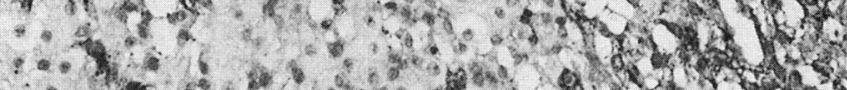

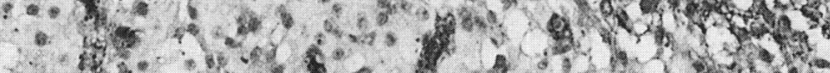

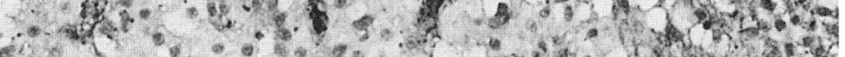
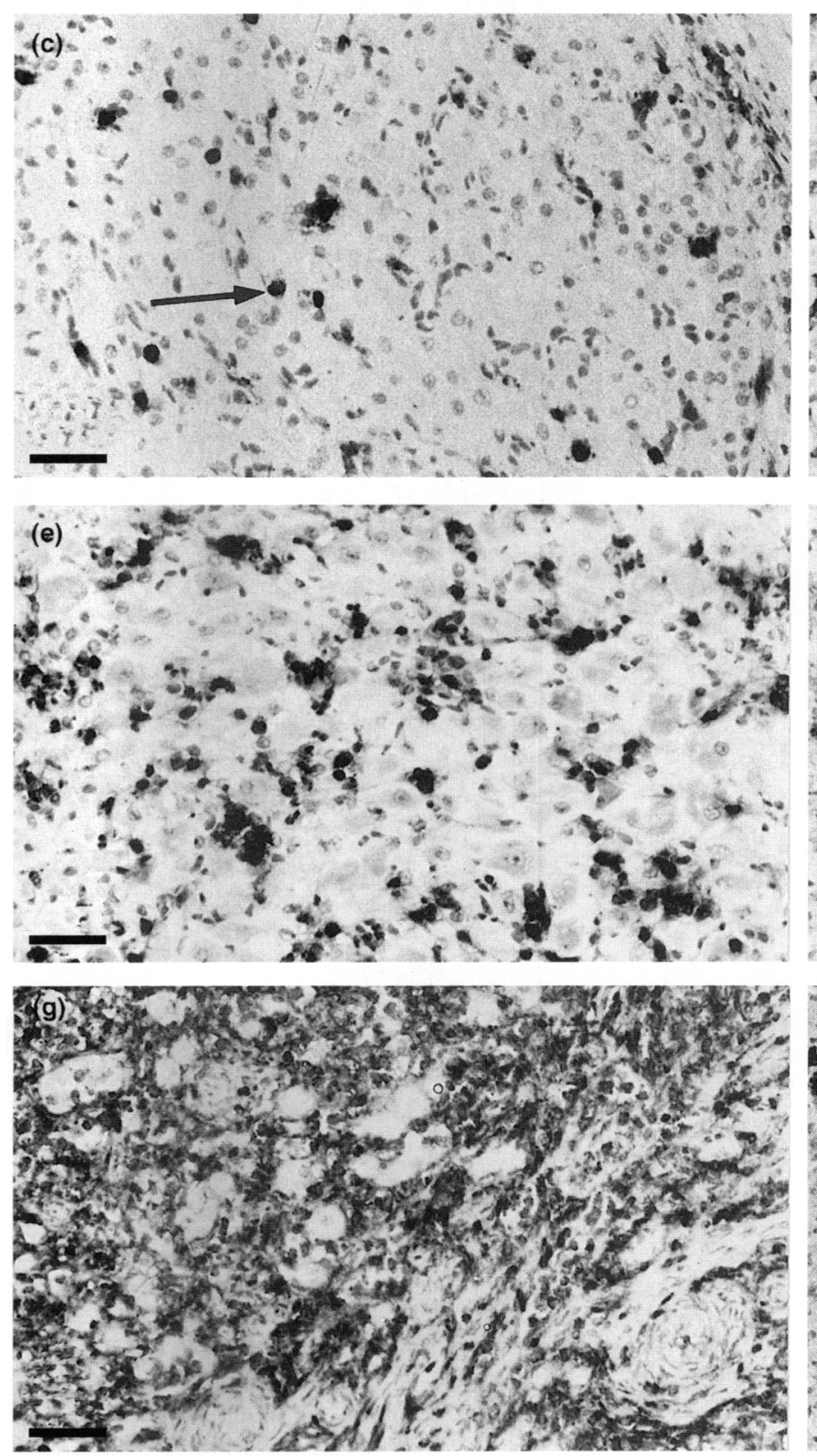

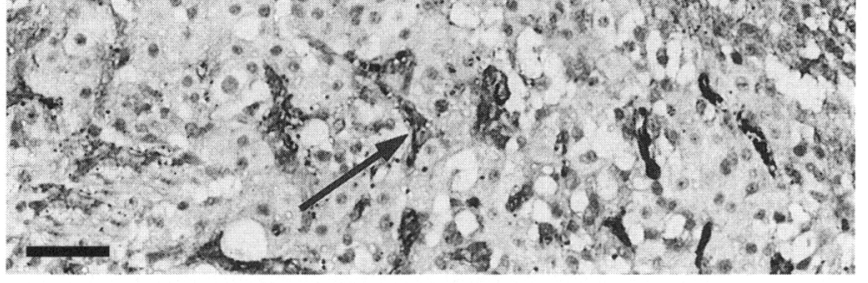

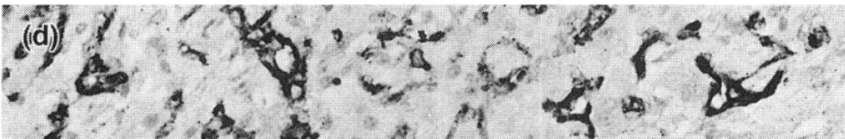

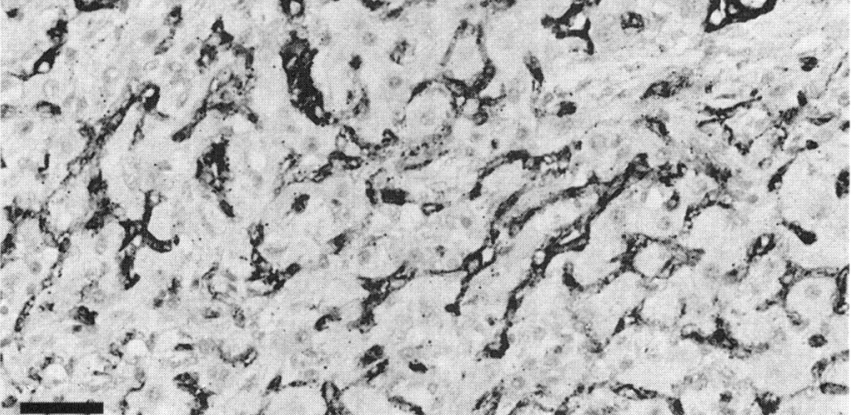

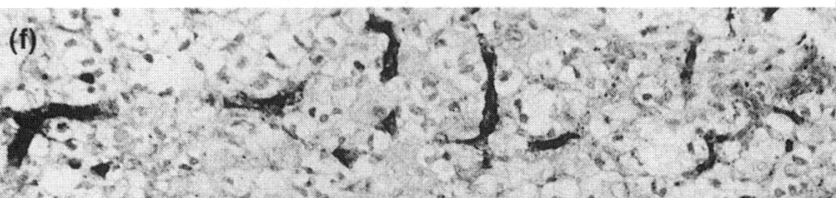

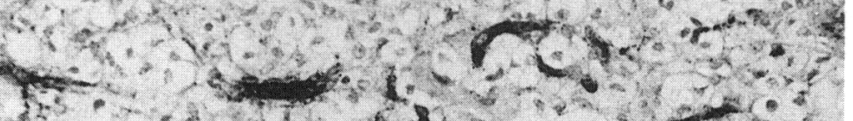
$x^{2}+1+1 \times 4$

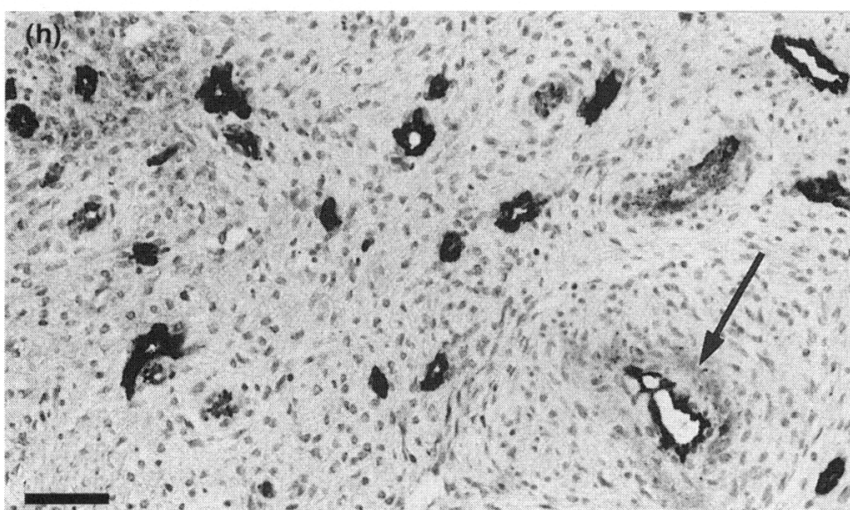

Fig. 2. Sections of bovine corpora lutea at different stages of the oestrous cycle. Indirect immunohistochemistry is for localization of the CD18 molecule $(a, c, e, g)$ and for factor VIIIr antigen $(b, d, f, h)$. (a) At the developmental stage, many positive cells are found in the septum. (b) The microvascular bed is moderately developed (arrow). (c) At the early secretory stage, the septum and the luteal tissue proper are sparsely populated by the CD18-positive cells (arrow). (d) A regular and dense capillary bed is apparent. (e) At the advanced stage of secretion more CD18-positive cells are seen than in (c). (f) The microvascular bed is reduced in comparison with (d). (g) At the regression stage, the CD18-positive cells are crowded. (h) The microvascular bed of (d) is replaced by shunt-like arterioles (arrow). Scale bars represent $50 \mu \mathrm{m}$. 
(a) $P^{3}$ s.

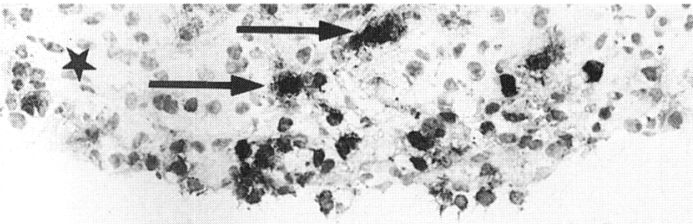

.96

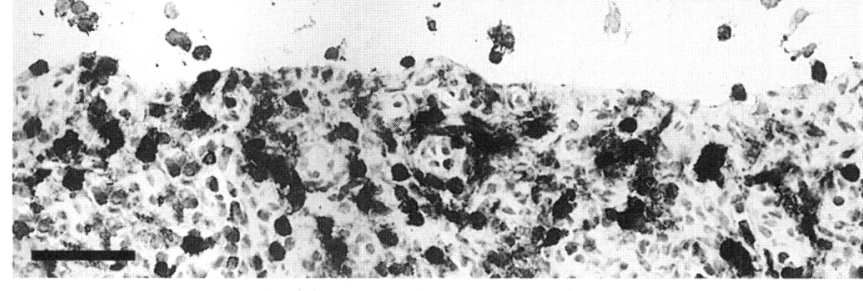

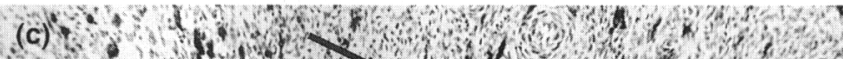

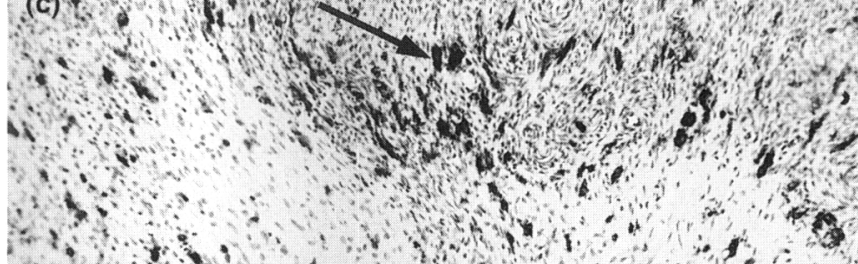

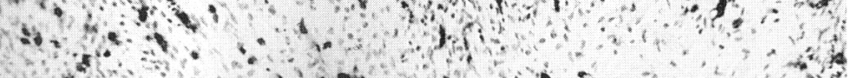
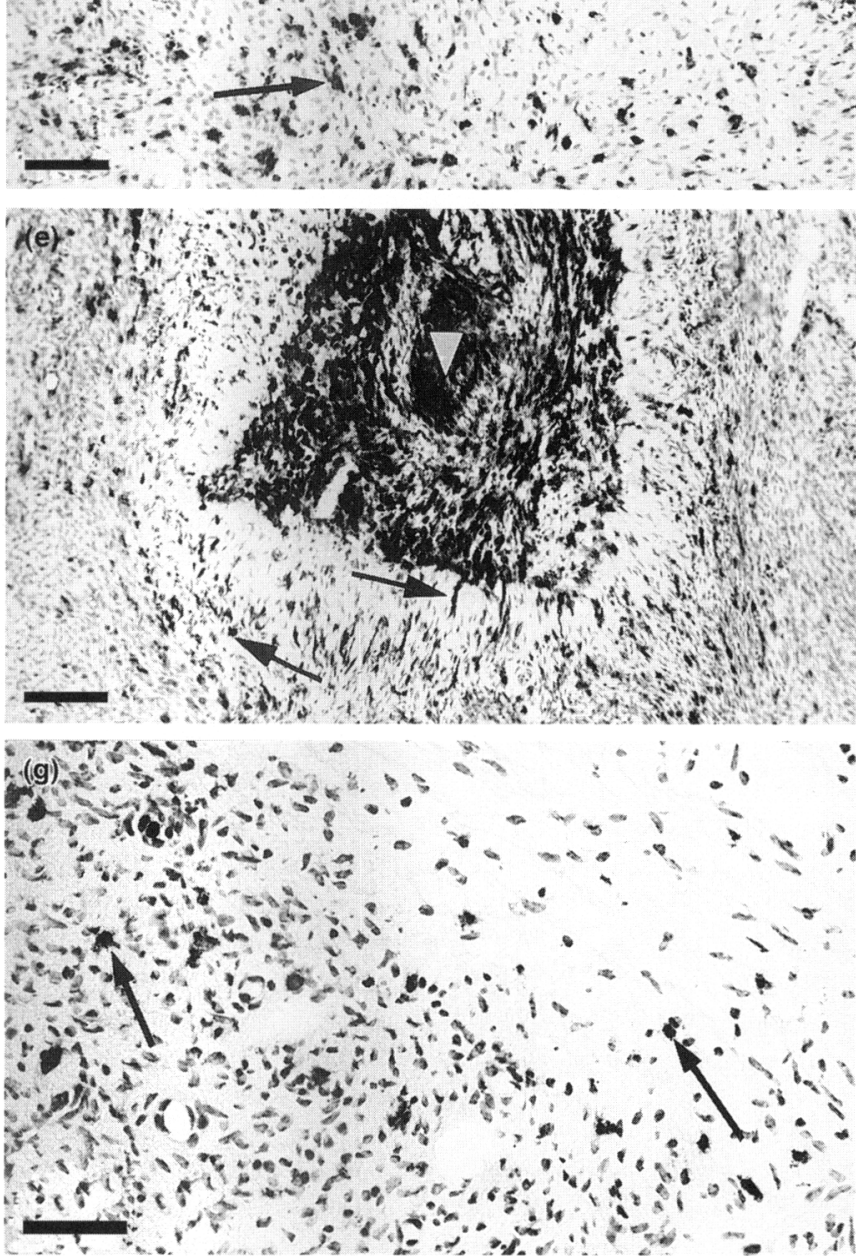

(b)

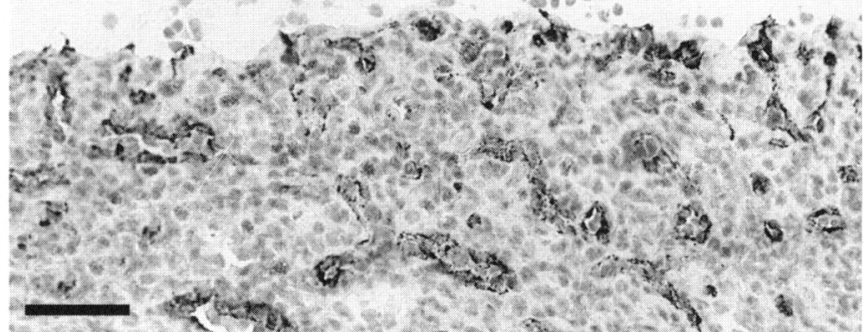

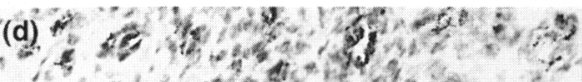

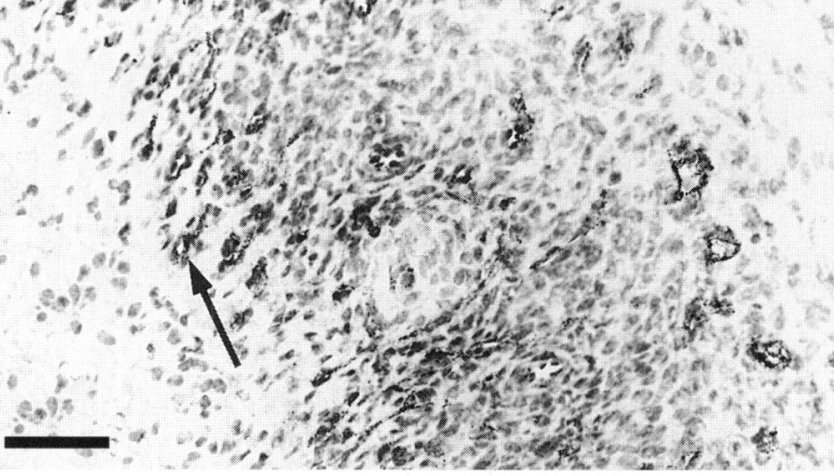

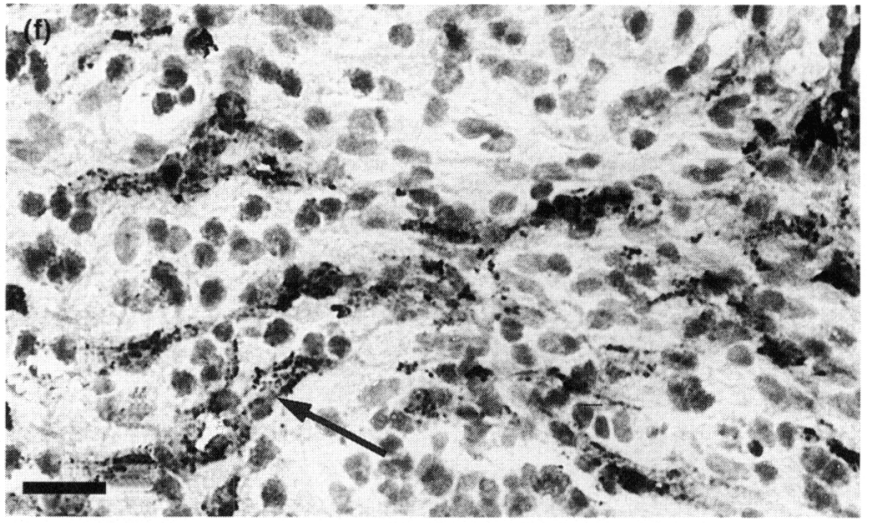

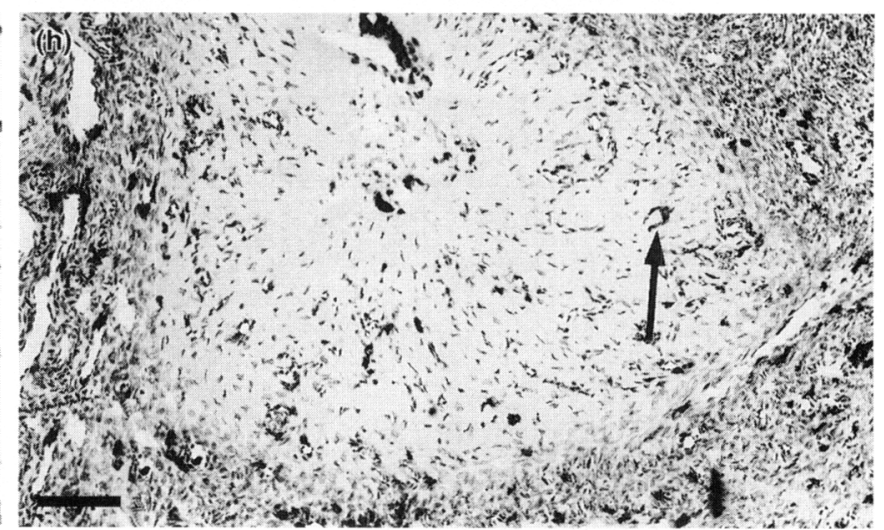

Fig. 3. Sections of bovine follicles at different stages of atresia stained by indirect immunohistochemistry. The sections on the left $(a, c, e, g)$ show the CD18-positive cells. The sections on the right $(b, d, f, h)$ demonstrate the microvessels in a corresponding area using a polyclonal antibody against factor VIIIr antigen. (a) The regressing antral follicle still maintains an antrum. The granulosa layer $(\star)$ has detached from the basal membrane. Many CD18-positive cells have invaded the hypertrophied thecal and the degenerating granulosa layers (arrows). (b) The hypertrophied theca exhibits a large number of microvessels. (c) A moderate number of CD18-positive cells are present in the hypertrophied theca and in the former antrum during fibrotic organization (arrows). (d) The hypertrophied theca as shown in (c) contains many microvessels (arrow). (e) This stage of fibrotic organization demonstrates the former antrum, which is crowded with CD18-positive cells (arrowhead), whereas the hypertrophied and hyalinized thecal layer display a moderate number of CD18-positive cells (arrows). (f) The leucocyte pool of (e) exhibits an arborization pattern likely to represent sprouting capillaries (arrow). (g) The follicle at the end of fibrotic organization is sparsely populated by

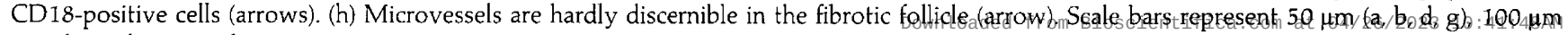
$(\mathrm{c}, \mathrm{e}, \mathrm{h})$ and $20 \mu \mathrm{m}(\mathrm{f})$. 
Table 2. Absolute number of positively stained cells in $0.5 \mathrm{~mm}^{2}$ areas of bovine corpus luteum and cortical stroma at different stages of the oestrous cycle

\begin{tabular}{lcccc}
\hline & & & Stage of oestrous cycle \\
\cline { 3 - 4 } Antigen & Specificity & $\begin{array}{c}\text { Development } \\
\text { (mean } \pm \text { SD; } n=7)\end{array}$ & $\begin{array}{c}\text { Secretion* } \\
\text { (mean } \pm \text { SD; } n=7)\end{array}$ & $\begin{array}{c}\text { Regression } \\
\text { (mean } \pm \text { SD; } n=3)\end{array}$ \\
\hline Corpus luteum & & & Crowded $^{\dagger}$ \\
CD18 & Pan-leucocytes & $59 \pm 16$ & $106 \pm 28^{\text {a }}$ & Crowded $^{\dagger}$ \\
CD45 & Pan-leucocytes & $50 \pm 15$ & $171 \pm 63^{\text {a }}$ & Crowded $^{\dagger}$ \\
Unknown & Pan-leucocytes & $45 \pm 15$ & $137 \pm 55^{\text {a }}$ & $172 \pm 13$ \\
CD2 & Lymphocytes & $10 \pm 6$ & $65 \pm 29^{\text {a }}$ & $31 \pm 13$ \\
CD3 & Lymphocytes & $2 \pm 2$ & $9 \pm 7$ & Crowded $^{\dagger}$ \\
CD14 & Monocytes & $19 \pm 6$ & $18 \pm 8$ & $120 \pm 25$ \\
Interstitial cortex & Pan-leucocytes & $137 \pm 46$ & $107 \pm 23$ & $178 \pm 25$ \\
CD18 & Pan-leucocytes & $290 \pm 81$ & $169 \pm 43$ & $176 \pm 25$ \\
CD45 & Pan-leucocytes & $181 \pm 46$ & $116 \pm 24$ & $108 \pm 47$ \\
Unknown & Lymphocytes & $52 \pm 18$ & $87 \pm 29$ & $45 \pm 13$ \\
CD2 & Lymphocytes & $37 \pm 15$ & $36 \pm 13$ & $31 \pm 19$ \\
CD3 & Monocytes & $35 \pm 15$ & $27 \pm 20$ & \\
CD14 & & & & \\
\hline
\end{tabular}

*Advanced secretion between days 11 and 17 of the oestrous cycle.

${ }^{\dagger}$ Single cells could not be distinguished.

${ }^{a} P<0.001$ versus development.

CDI4-positive cells, represented a minor proportion of the CDI8-positive cells at the development and secretion stages. The CD14-positive cells suddenly could not be observed in the regressing corpus luteum. The pool of lymphocytes was located with specific antibodies against CD2 and CD3 molecules. There were approximately 17 times more CD2-positive cells at the regressive stage compared with that at the developmental stage. Approximately fivefold more CD2positive cells were counted than CD3-positive cells. No positive response was obtained with the antibodies against CD4 or CD8. The total number of monocytes (CD14-positive) and lymphocytes (CD2- and CD3-positive) corresponded to about $50 \%$ of the CD18-positive leucocytes during the development and secretion stages.

Interstitial cortex. The number of positively stained cells did not increase significantly among the different stages of the oestrous cycle, when comparing the results for the different antibodies (Table 2).

\section{Discussion}

Neutrophils and eosinophils as well as mast cells have been detected by morphology in the theca of preovulatory follicles from rats, hamsters and rabbits (Nakamura et al., 1987; Cavender and Murdoch, 1988; Murdoch and McCormick 1989; Brännström et al., 1993). Neutrophils and eosinophils have been identified by immunocytochemistry in the corpora lutea of rats and humans (Murdoch, 1987; Brännström et al., 1994a, b). The present study of leucocyte distribution in the bovine ovary was unable to locate neutrophils or eosinophils selectively due to lack of a specific antibody. However, the presence of granulo- cyte subsets needs to be considered as well, because, in histological sections of bovine corpora lutea, the number of CD18-positive leucocytes exceeded the number of lymphocytes and monocytes.

Small numbers of $\mathrm{T}$ lymphocytes of the cytotoxic CD8 subtype have been noticed in preovulatory follicles and in secretory corpora lutea (Brännström et al., 1993, 1994a, b). Compared with at the secretory stage, these lymphocytes remained sparsely distributed at the regressing stage, as reported in rats, rabbits and humans (Bagavandoss et al., 1990; Brännström et al., 1994a, b). The function of the cytotoxic lymphocytes appears to be connected with the phagocytic function of macrophages which secrete a tumour necrosis factor in the regressing corpus luteum of the rabbit (Bagavandoss et al., 1988). Neither CD4-positive nor CD8-positive lymphocytes were located in the present study with the recommended antisera, in spite of positive controls with liver sections. The CD3-positive cells observed in the bovine corpus luteum appear to be double negative $T$ cells, whereas the CD2-positive cells are probably indicative of non- $B$ non- $T$ lymphocytes. Since the CD2-positive cells increased in number between the development stage and the regression stage, and because in the corresponding interstitial cortex, the number of lymphocytes did not vary significantly, a luteal mechanism may have selectively recruited lymphocytes. We have speculated as to whether the CD2-positive cells belong to the group of natural killer-like cells also recognized as large granular lymphocytes. These are reported as populating the late secretory phase of the endometrium and are present there during the first trimester of pregnancy (Parr et al., 1991; Croy and Kiso, 1993; Haynes et al., 1995).

Resident leucocytes are able to produce influential factors that may be involved in the essential ovarian events of growth 
and rupture of follicles, of the corpus luteum life cycle, and of follicular atresia (Adashi, 1990, 1991). These events represent fundamental mechanisms of cell biology that give insight into growth, remodelling and tissue degradation by controlling angiogenesis and angioregression, as well as by the formation and degradation of the extracellular matrix.

The development of primordial follicles into primary follicles is controlled by locally activated growth factors and cytokines (Hirshfield, 1991). Among these, the epidermal growth factor appears to be crucial for the growth of primordial follicles into primary follicles, as reported in cultured neonatal mouse ovaries (Eppig and O'Brien, 1996). Leucocytes such as monocytes and endothelial cells are known to secrete a large variety of growth factors and cytokines (Nathan, 1987; Fajardo, 1989). Therefore, we suggest that the outer layer of the bovine interstitial cortex, with its negligible number of CD18-positive cells and a sparsely vascularised zone, represents a security zone that keeps primordial follicles in a stage of dormancy.

In preovulatory follicles, two layers of a dense capillary bed are present in the thecal wall, as has been shown by means of microvessel corrosion casts (Kitai et al., 1985; Löseke and Spanel-Borowski, 1996). Microvessels of preovulatory and freshly ovulated follicles dilate and increase in permeability (Cavender and Murdoch, 1988). These vessel changes occur at the time of the basal membrane breakdown caused by locally activated proteolytic enzymes, which are secreted mainly by granulosa cells (Tsafriri et al., 1993). Using in situ hybridization or the PCR technique, others have shown a distinct expression of mRNA encoding vascular endothelial growth factor in the theca or in the area of the basal membrane (Ravindranath et al., 1992; Koos, 1995). We suggest that, for the CD18-positive cells aligned along the basal membrane of a preovulatory follicle, particular leucocyte subsets secrete factors for vasodilatation, vessel permeability, and basal membrane breakdown during the ovulatory period.

The freshly ovulated follicle transforms itself into a corpus luteum by means of two conspicuous processes: (i) vessel sprouting with vessel growth towards the centre of the antrum (Findlay, 1986; Koos, 1989; Reynolds et al., 1992; Löseke and Spanel-Borowski, 1996), and (ii) luteinization of granulosa and thecal cells (Brannian and Stouffer, 1991). An angiogenic factor has been detected in the medium of primary granulosa cell cultures obtained from freshly ovulated follicles (Rone and Goodman, 1990; Katz et al., 1992). This factor may have been released from accidentally cocultured leucocyte subsets, for example macrophages with a high angiogenic potential (Sunderkötter et al., 1994). The LH surge and the binding of this gonadotrophin to granulosa and thecal cells trigger and maintain the luteinization process (Brannian and Stouffer, 1991). In addition, cultured granulosa cells produce more progesterone in coculture with peritoneal or ovarian macrophages (Kirsch et al., 1981; Halme et al., 1985). Since shortly after ovulation, CD18-positive cells invade the granulosa layer of a developing corpus luteum (as observed in the present study), particular leucocyte subsets, such as the monocytes, may support the vigorous vessel sprouting and the luteinization of the granulosa and thecal cells.

In the present study, a large number of CD18-positive cells was observed in the late secretory corpus luteum. This number increased rapidly in the regressing corpus luteum, probably as the result of an augmented recruitment of macrophages. The significance of their appearance is in accordance with their known function of phagocytosing the dying and dead cells of a corpus luteum (Paavola, 1979; Hehnke et al., 1994). In addition, although capillaries disappear, arterioles with a distinct media form. These look like shunt vessels which possibly reduce and then cut off the blood flow to the regressing corpus luteum. These findings suggest that macrophages in a regressing corpus luteum, together with the other leucocyte subsets, are involved in arteriole development. The high angiogenic activity found in extracts of regressing bovine corpora lutea (Redmer et al, 1988) may have been derived from such leucocytes.

Atresia of antral follicles is generally thought to be related to the presence of a poor microvascular bed. We want to exclude this statement from the association with the thecal cell hypertrophy, since it shows a considerable number of seemingly intact microvessels. The delicate factor VIIIr-positive arborization pattern, which is reminiscent of capillary sprouts, indicates an angiogenic process in the former antrum. Since the antrum was crowded with CD18-positive cells, these cells, apart from their phagocytic function, may have induced vessel sprouting. The transient angiogenic event in follicular atresia is then followed by a fibrotic process leading to hyalinization. During tissue repair, resident macrophages with phagocytic activity produce fibrogenic cytokines that stimulate collagen synthesis (Kovacs, 1991). For this reason, we suggest that the heterogeneous pool of CD18-positive cells is responsible for the hyalinization process in regressing follicles and in corpora lutea. In other words, the steps of folliclular atresia are similar to wound repair and to fibrotic disorders such as atherosclerosis, pulmonary fibrosis, liver cirrhosis and rheumatic arthritis.

In conclusion, resident leucocytes of different subsets appear to play a dominant role in the control of ovarian processes.

The authors are indebted to M. Saxer for technical assistance, to H-J. Stöcklin for the photographic work and to F. Steel for experienced corrections in English grammar and style. The study was financially supported by the Swiss National Foundation, Grant no. 31-43 146.95.

\section{References}

Adashi EY (1990) The potential relevance of cytokines to ovarian physiology: the emerging role of resident ovarian cells of the white blood cell series Endocrine Reviews 11 454-463

Adashi EY (1991) Do cytokines play a role in the regulation of ovarian function? Progress in NeuroEndocrinImmunology 3 11-17

Bagavandoss P, Kunkel SL, Wiggins RC and Kleyes PL (1988) Tumor necrosis factor- $\alpha$ (TNF- $\alpha$ ) production and localization of macrophages and T lymphocytes in the rabbit corpus luteum Endocrinology 122 1185-1187

Bagavandoss P, Wiggins RC, Kunkel SL, Remick DG and Keyes PL (1990) Tumor necrosis factor production and accumulation of inflammatory cells in the corpus luteum of pseudopregnancy and pregnancy in rabbits Biology of Reproduction 42 367-376

Bosman FT (1993) Integrins: cell adhesives and modulators of cell function Histochemical Journal 5 469-477

Brannian JD and Stouffer RL (1991) Cellular approaches to understanding the function and regulation of the primate corpus luteum Seminars in Reproductive Endocrinolgy 9 341-351

Brännström M, Mayrhofer G and Robertson SA (1993) Localization of leucocyte subsets in the rat ovary during the periovulatory period Biology of Reproduction 48 277-286 
Brännström M, Giesecke L, Moore IC, Van den Heuvel $\mathrm{CJ}$ and Robertson SA (1994a) Leucocyte subpopulations in the rat corpus luteum during pregnancy and pseudopregnancy Biology of Reproduction 50 1161-1167

Brännström M, Pascoe V, Norman RJ and McClure N (1994b) Localization of leucocyte subsets in the follicle wall and in the corpus luteum throughout the human menstrual cycle Fertility and Sterility 61 488-495

Cavender JL and Murdoch WJ (1988) Morphological studies of the microcirculatory system of periovulatory ovine follicles Biology of Reproduction 39 989-997

Croy BA and Kiso Y (1993) Granulated metrial gland cells: a natural killer cell subset of the pregnant murine uterus Microscopy Research and Technique 25 $189-200$

Eppig JJ and O'Brien MJ (1996) Development in vitro of mouse oocytes from primordial follicles Biology of Reproduction 54 197-207

Fajardo LF (1989) The complexity of endothelial cells Journal of Clinical Pathology 92 241-250

Findlay JK (1986) Angiogenesis in reproductive tissues Journal of Endocrinology $111357-366$

Halme J. Hammond MG, Syrop CH and Talbert LM (1985) Peritoneal macrophages modulate human granulosa-luteal cell progesterone production Journal of Clinical Endocrinology and Metabolism 61 912-916

Haynes MK, Flanagan MT, Perussia B, Jackson LG and Smith JB (1995) Isolation of decidual lymphocytes from chorionic villus samples: phenotypic analysis and growth in vitro. American Journal of Reproductive Immunology 33 190-199

Hehnke KE, Christenson LK, Ford SP and Taylor M (1994) Macrophage infiltration into the porcine corpus luteum during prostaglandin $\mathrm{F}_{2 i}$-induced luteolysis Biology of Reproduction 50 10-15

Hirshfield AN (1991) Development of follicles in the mammalian ovary International Review of Cyotology 124 43-101

Hughes FM and Gorospe WC (1991) Biochemical identification of apoptosis (programmed cell death) in granulosa cells: evidence for a potential mechanism underlying follicular atresia Endocrinology 129 2415-2422

Juengel JL, Garverick HA, Johnson AL, Youngquist RS and Smith MF (1993) Apoptosis during luteal regression in cattle Endocrinology 132 249-254

Katz E, Goodman AL, García J and Rone JD (1992) Evidence for the production of a nonsteroidal endotheliotropic factor by human granulosa cells in culture Ferility and Sterility 57 107-112

Kirsch TM, Friedman AC, Vogel RL and Flickinger GL (1981) Macrophages in corpora lutea of mice: characterization and effects on steroid secretion Biology of Reproduction 25 629-638

Kitai H, Yoshimura Y, Wright KH, Santulli R and Wallach EE (1985) Microvasculature of preovulatory follicles: comparison of in situ and in vitro perfused rabbit ovaries following stimulation of ovulation American Journal of Obstetrics and Gynecology 152 889-895

Koos RD (1989) Potential relevance of angiogenic factors to ovarian physiology Seminars in Reproductive Endocrinology $729-40$
Koos RD (1995) Increased expression of vascular endothelial growth/ permeability factor in the rat ovary following an ovulatory gonadotropin stimulus: potential roles in follicle rupture Biology of Reproduction $\mathbf{5 2}$ 1426-1435

Kovacs EJ (1991) Fibrogenic cytokines: the role of immune mediators in the development of scar tissue Immunology Today 12 17-23

Löseke A and Spanel-Borowski K (1996) Simple or repeated induction of superovulation: a study on ovulation rates and microvessel corrosion casts in ovaries of golden hamsters Annals of Anatomy 178 5-14

Murdoch WJ (1987) Treatment of sheep with prostaglandin $F_{20}$ enhances production of a luteal chemoattractant for eosinophils American Journal of Reproductive Immunology 15 52-56

Murdoch WJ and McCormick RJ (1989) Production of low molecular weight chemoattractants for leucocytes by periovulatory ovine follicles Biology of Reproduction 40 86-90

Nakamura Y, Smith M, Krishna A and Terranova PF (1987) Increased number of mast cells in the dominant follicle of the cow: relationships among luteal, stromal and hilar regions Biology of Reproduction 37 546-549

Nathan CF (1987) Secretory products of macrophages Journal of Clinical Investigation 79 319-326

Paavola LG (1979) The corpus luteum of the guinea pig. Fine structure of macrophages during pregnancy and postpartum luteolysis and phagocytosis of luteal cells American Journal of Anatomy 154 337-364

Parr EL, Parr MP, Zheng LM and Young JD-E (1991) Mouse granulated metrial gland cells originate by local activation of uterine natural killer lymphocytes Biology of Reproduction 44 834-841

Ravindranath N, Little-Ihrig L, Phillips HS, Ferrara N and Zeleznik AJ (1992) Vascular enodthelial growth factor messenger ribonucleic acid expression in the primate ovary Endocrinology $131254-260$

Redmer DA, Grazul AT, Kirsch JD and Reynolds LP (1988) Angiogenic activity of bovine corpora lutea at several stages of luteal development Journal of Reproduction and Fertitity 82 627-634

Reynolds LP, Killilea SD and Redmer DA (1992) Angiogenesis in the female reproductive system FASEB Journal 6 886-892

Ricken AM, Spanel-Borowski K, Saxer M and Huber PR (1995) Cytokeratin expression in bovine corpora lutea Histochemistry 103 345-354

Rone JD and Goodman AL (1990) Preliminary characterization of angiogenic activity in media conditioned by cells from luteinized rat ovaries Endocrinology $127 \quad 2821-2828$

Simón C, Frances A, Piquette G and Polan ML (1994) Immunohistochemical localization of the interleukin-I system in the mouse ovary during follicular growth, ovaluation, and luteinization Biology of Reproduction 50 449-457

Sunderkötter C, Steinbrink K, Goebeler M, Bhardwaj R and Sorg C (1994) Macrophages and angiogenesis Journal of Leukocyte Biology 55 410-422

Tsafriri A, Chun S-Y and Reich R (1993) Follicular rupture and ovulation. In The Ovary pp 227-244 Eds EY Adashi and PC Leung. Raven Press, New York 